TI 2011-059/3

Tinbergen Institute Discussion Paper

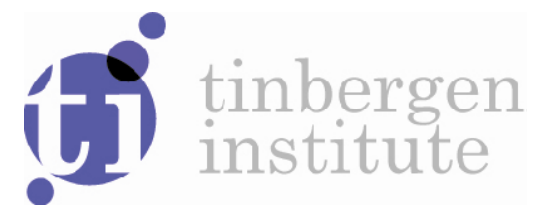

\title{
Congesting Pricing in a Road and Rail Network with Heterogeneous Values of Time and Schedule Delay
}

Vincent van den Berg

Erik T. Verhoef 
Tinbergen Institute is the graduate school and research institute in economics of Erasmus University Rotterdam, the University of Amsterdam and VU University Amsterdam.

More TI discussion papers can be downloaded at http://www.tinbergen.nl

Tinbergen Institute has two locations:

Tinbergen Institute Amsterdam

Gustav Mahlerplein 117

1082 MS Amsterdam

The Netherlands

Tel.: +31(0)205251600

Tinbergen Institute Rotterdam

Burg. Oudlaan 50

3062 PA Rotterdam

The Netherlands

Tel.: +31(0)10 4088900

Fax: +31(0)104089031

Duisenberg school of finance is a collaboration of the Dutch financial sector and universities, with the ambition to support innovative research and offer top quality academic education in core areas of finance.

DSF research papers can be downloaded at: http://www.dsf.nl/

Duisenberg school of finance

Gustav Mahlerplein 117

1082 MS Amsterdam

The Netherlands

Tel.: +31(0)20 5258579 


\title{
Congestion pricing in a road and rail network with heterogeneous values of time and schedule delay
}

\author{
Version of 13 April 2012 \\ Vincent A.C. van den Berg* \\ Department of Spatial Economics \\ VU University Amsterdam \\ De Boelelaan 1105 \\ $1081 \mathrm{HV}$ Amsterdam \\ +31-20-5986160 \\ v.a.c.vanden.berg@vu.nl \\ Erik T. Verhoef ${ }^{* *}$ \\ Department of Spatial Economics \\ VU University Amsterdam \\ De Boelelaan 1105 \\ 1081 HV Amsterdam \\ $+31-20-5986090$ \\ e.t.verhoef@vu.nl
}

\begin{abstract}
We analyse congestion pricing in a road and rail network, where the two modes are imperfect substitutes. On the road there is bottleneck congestion; in each train there is crowding congestion. We model two dimensions of preference heterogeneity, where these two dimensions have opposite effects on the welfare impact of congestion pricing and lead to different distributional effects. The distributional effects also differ between road and rail. On the road, pricing is generally more beneficial with a higher value of time or schedule delay. In the train, pricing has no distributional effects or is less beneficial with a higher value.
\end{abstract}

JEL codes: D62, H23, L11, R41, R48

Keywords: Congestion Pricing; Car Travel; Train Travel; Heterogeneity; Distributional Effects

\footnotetext{
* Corresponding author.

** Affiliated to the Tinbergen Institute, Roetersstraat 31, 1018 WB Amsterdam.
} 


\section{Introduction}

Road congestion is one of the most important problems in urban areas. Small and Verhoef (2007) find that congestion caused the largest marginal external cost due to car travel in the US in 2005: of this total 65\% was from congestion, 6\% was environmental, and 25\% from accident externalities. Transport pricing is generally seen as one of the main instruments that a government could use to address externalities and to affect modal choices. In studying such pricing measures, it is important to take into account the dynamics of departure time choice, substitute modes, and preference heterogeneity. Therefore, our model of (first- or second-best) congestion pricing, ${ }^{1}$ where the modes are imperfect substitutes, takes all these issues into account.

Although the efficiency argument for congestion pricing is firmly established, it is seldom applied in practise. Often, proposals meet fierce resistance, and it is important that analysis helps identifying where such resistance is strongest and why. Distributional effects are a reason why congestion pricing often meets resistance. When pricing reduces travel times and increases monetary costs, an individual is better off when her value of time is higher. Since the value of time generally increases with income, this is often viewed as implying that the poor lose and the rich gain from road pricing (see, e.g., Layard, 1977). However, things might not be as simple as this. For example, Vickrey (1973) analyses a bottleneck model with fixed demand. He studies what we will call "proportional heterogeneity". In this setting, the values of time $(\alpha)$ and schedule delay $(\beta)$ vary over individuals in fixed proportions. Because these values are the ratio of a marginal utility of a time component and the marginal utility of income, proportional heterogeneity could stem from differences in the marginal utility of income due to differences in incomes. Surprisingly, in this setting, first-best tolling brings a strict Pareto improvement: all users gain - except those with the lowest values, who are unaffected.

De Palma and Lindsey (2002) study heterogeneity in the value of time with fixed values of schedule delay. We call this heterogeneity "ratio heterogeneity", as it implies heterogeneity in the ratio of value of time to value of schedule delay $\mu_{i}=\alpha_{i} / \beta$. This ratio has an interpretation: it reflects the willingness to accept greater schedule delays in order to reduce travel time. Heterogeneity in $\mu$ could for example result from differences in possibilities to use in-vehicle time productively or differences in the tightness of scheduling constraints: e.g. having small children versus not, working on an assembly line versus in an office, and travelling to a hospital appointment versus to go shopping. When only this type of heterogeneity exists, tolling is harmful for users: under fixed demand, all users lose - except those with the highest value of time, who are unaffected (see de Palma and Lindsey, 2002).

${ }^{1}$ Although we call the two modes rail and car, they can be any two modes that have no congestion interactions. The two modes could be any two of: express way, (arterial) road, air, (light) rail, and metro; but not bus and car, as these use the same road. 
Besides these distributional effects, heterogeneity can also lead to a higher or lower welfare gain from a policy, as well as affect the relative performance of policies (see, e.g., Arnott, de Palma and Lindsey (1988), Small and Yan (2001), and Verhoef and Small (2004)). Hence, heterogeneity affects both the aggregate as well as the distributional effects of policies.

Van den Berg and Verhoef (2011a) show that price sensitivity of demand changes the effects of heterogeneity in the bottleneck model. With proportional heterogeneity, first-best tolling lowers the generalised prices for users with high values and as a result they demand more travel, which increases congestion and makes tolling harmful for drivers with low values. This paper finds that also the amount of substitutability of the two modes changes the effects of pricing, and how heterogeneity influences these effects. Hence, our analysis confirms that it is not only important to control for heterogeneity and price sensitivity of demand, but also for the substitutability between different modes.

We study both first-best pricing of both modes and second-best pricing of one mode only. The latter bears close correspondence to second-best pricing of one of two parallel roads. Such roads are usually closer substitutes than two modes. Braid (1996) was one of the first to study this second-best policy in the dynamic bottleneck model. The welfare-maximising toll has a timevariant term that equals the congestion externality and a time-invariant term that is negative. This negative term attracts users away from the unpriced link where marginal social cost is above private cost, and therewith increases welfare.

Besides being an imperfect substitute to car travel, public transport also needs a different specification of user costs than road transport. To accommodate departure time choice, we need a dynamic model of public transport. Various such models have been proposed in the literature. Kraus and Yoshida (2002) develop a model with queuing at the platform. Their model is similar to the bottleneck model. Also here queuing is a pure loss and dynamic pricing completely eliminates it. Tabuchi (1993), Huang (2000), and Rouwendal and Verhoef (2004) use a parallel road and rail track. Tabuchi (1993) has bottleneck congestion on the road and no congestion in the single train service, which arrives exactly at the preferred arrival time, $t^{*}$. The train operator's costs consist of fixed and per-user cost. If the train fare equals average operating cost, the secondbest road toll is the standard time-variant toll plus a positive term that pushes users to the train. This difference from Braid's (1996) result stems from the fact that in the train the average-cost fare is above marginal costs, and an increase in the number of users lowers average cost, which is why a positive addition to the road toll that pushes drivers to the train is second-best optimal. This shows that seemingly similar policies in road transport and public transport may work out rather differently, which makes it important to take into account when there are different modes. Huang (2000) considers two user groups with different values of time, schedule delay, and crowding. The road has dynamic bottleneck congestion. The single train service arrives at $t^{*}$ and 
has crowding congestion: that is costs associated with being in a crowded train. Rouwendal and Verhoef (2004) also use crowding congestion. However, they use a static road model, and car and train are imperfect substitutes.

We study a parallel road and rail line using a dynamic model. On the road there is bottleneck congestion. In each train service there is crowding congestion. Our train model is dynamic, which differs from Tabuchi (1993) and Huang (2000). We consider profit maximisation on only road or rail, which appears to have been ignored for rail-road networks so far. In reality, rail companies are often private or at least partly privatised; therefore, profit maximisation by a rail operator seems important. This relevance increases when rail franchises are auctioned off to the highest bidder, as this drives the winning firm towards profit maximisation. Also private provision of roads seems to become an increasingly popular policy option.

We find that heterogeneity affects road and rail differently. Without congestion pricing, the mean price of car travel decreases with the degree of ratio heterogeneity; while proportional heterogeneity has no effect. Conversely, the average price of train travel is unaffected by ratio heterogeneity, but decreases with the degree of proportional heterogeneity. For second-best pricing, we find that the relative efficiency of road pricing only decreases with proportional heterogeneity (relative efficiency is defined as the welfare gain of a policy relative to the firstbest gain). This contrasts with a result with two parallel bottlenecks in Van den Berg and Verhoef (2011a), where the relative efficiency of single-link pricing increases with proportional heterogeneity. As we will explain, this difference is due to the assumption that two roads are perfect substitutes, whereas road and rail are imperfect substitutes in our analysis.

The paper is arranged as follows. Section 2 discusses the analytical model for car travel. Section 3 derives the model for rail travel. Section 4 describes the numerical set-up. Sections 5 and 6 analyse the numerical model for respectively proportional and ratio heterogeneity. These sections also give sensitivity analyses on the degree of heterogeneity. Section 7 presents further sensitivity analyses. Section 8 concludes.

\section{The model set-up}

Our model considers one road and one rail track that connect a single origin and destination. To simplify the analysis, we analyse the two types of heterogeneity separately: we first study ratio heterogeneity and then proportional heterogeneity. Van den Berg and Verhoef (2011a) find that the qualitative effects of the one type of heterogeneity are not affected by the degree of the other type. Still, the separate analysis makes it harder to examine distributional effects, as these depend on the extents of both types of heterogeneity.

We use a deterministic model, without uncertainty or risk-aversion. We only look at the shortterm policy of price setting. We ignore long-term policies such as train schedule or road, rail- 
track and train capacity. Furthermore, we assume that rail-operating costs are a constant amount per user, and there are no fixed costs. We ignore heterogeneity in the value of crowding congestion. To simplify the rail model, we assume that users cannot arrive after the common preferred arrival time $t^{* 2}$.

The two modes are imperfect substitutes. The inverse demand $\left(I D_{i j}\right)$ for user type $i$ of mode $j$ is

$$
I D_{i j}=A_{i j}+\frac{b_{i j}}{B_{j}} n_{i j}+\frac{e_{i j}}{E_{j}} n_{i k}
$$

where $B_{j}$ and $E_{j}$ are scaling factors used in calibration, and $n_{i l}$ is the density of type $i$ users on mode $l$. An user type comprises of all the users with a certain combination of values of schedule delay $(\beta)$ and time $(\alpha)$. The value of time give monetary value of an hour of travel time; the value of schedule delay the monetary value an hour earlier arrival than the preferred arrival time $t^{*}$. Both $b_{i j} / B_{j}$ and $e_{i j} / E_{j}$ must be negative (if $e_{i j} / E_{j}$ were positive, the two modes would be complements). ${ }^{3}$ Total consumer surplus is the integral of the surplus per type. Welfare is total consumer surplus plus profits. In the deterministic equilibrium, the generalised price (or price for brevity) of each modes equals the value of its inverse demand function. The generalised price is the sum of toll on the road or the fare in the train and the generalised cost.

\section{Introducing heterogeneity: analytical exposition for a road with a bottleneck}

Before we turn to the full model we will present sub-models for road and public transport separately. We start with the former, and use the exposition to summarise the insights from the literature on the impacts of heterogeneity in the Vickrey bottleneck model.

\subsection{Ratio heterogeneity and pricing of a single bottleneck}

The first type of heterogeneity we consider is what we call "ratio heterogeneity". This refers to heterogeneity in the value of time $(\alpha)$ with a fixed value of schedule delay $(\beta)$ : the ratio follows $\mu_{i} \equiv \alpha_{i} / \beta{ }^{4}$ This heterogeneity should not be viewed as stemming from income differences, as income differences should also lead to heterogeneity in $\beta$. We use subscript $i$ to indicate a group

\footnotetext{
${ }^{2}$ With late arrivals, the effect on prices of the number of early and late train services is asymmetric and the exact form of the price equation depends on the ratio of the values of schedule delay early and late. Arnott and Kraus (1993; 1995), Kraus and Yoshida (2002), and Kraus (2003) also use this simplification. Although the restriction of no late arrival is unrealistic; it does not affect the general results of the bottleneck (see Arnott and Kraus (1993, footnote 12)) or the crowding model.

${ }^{3}$ Following Kraus (2003), we impose that the cross-substitution effects are the same for both modes for all types of users (i.e. $\partial D_{i j} / \partial P_{i k}=\partial D_{i k} / \partial P_{i j}$, where $D_{i j}$ is the demand function and $P_{i j}$ the price), and there are no income effects. Users are utility maximisers, and consequently $\partial D_{i j} / \partial P_{i j} \cdot \partial D_{i k} / \partial P_{i k}>\partial D_{i j} / \partial P_{i k} \cdot \partial D_{i k} / \partial P_{i j}$ must hold. Under these assumptions, two-good consumer surplus for a type of user is the line integral of the two inverse demands minus total costs for this type of users.

${ }^{4}$ Here, as is conventional in the literature, we assume $\alpha_{i}>\beta$ for all $i$, as otherwise the standard no-toll equilibrium would not hold.
} 
of users with the same value of time, so $P_{i}$ is the price for users with a value of time of $\alpha_{i}$. The price is the sum of the possible toll and the generalised cost. In the analytical road models, the generalised cost is the sum of travel delays cost and schedule delay cost. The numerical models will add free-flow travel time and car-operating costs.

While our full model uses continuous distributions, it is insightful to consider first a simplified graphical example with only two types of drivers and fixed demand. Figure 1 illustrates this situation. The left panel gives the development of travel time in the No-Congestion-Pricing (NCP) equilibrium; the right panel shows the first-best (FB) toll. The lines can be interpreted as iso-price lines (i.e. lines along which the price is constant). A higher line naturally implies a higher price. The lines are derived from the condition that the price must be constant for group $i$ during the entire period its users travel, and not lower for other arrival times. In the NCP equilibrium, this condition requires travel times by arrival time to grow at a rate $1 / \mu_{i} \equiv \beta / \alpha_{i}$ when group $i$ travels. The High group has a higher value of time and thus a higher ratio $\mu_{H} \equiv \alpha_{H} / \beta$. In the NCP case, the groups travel temporally separated. The high $\mu_{H}$ of the High group means that they choose to arrive early to avoid long travel times, and reversely for the Low group. FB tolling, in the right panel, removes all queuing (see, e.g., Arnott, de Palma and Lindsey, 1988). Now the groups travel jointly, as there are only scheduling costs and tolls, both of which they are assumed to value equally. This requires the toll to increase with $\beta$, so that travel delays that are always zero constitutes the dynamic equilibrium.

Figure 1: Example of ratio heterogeneity with two discrete groups

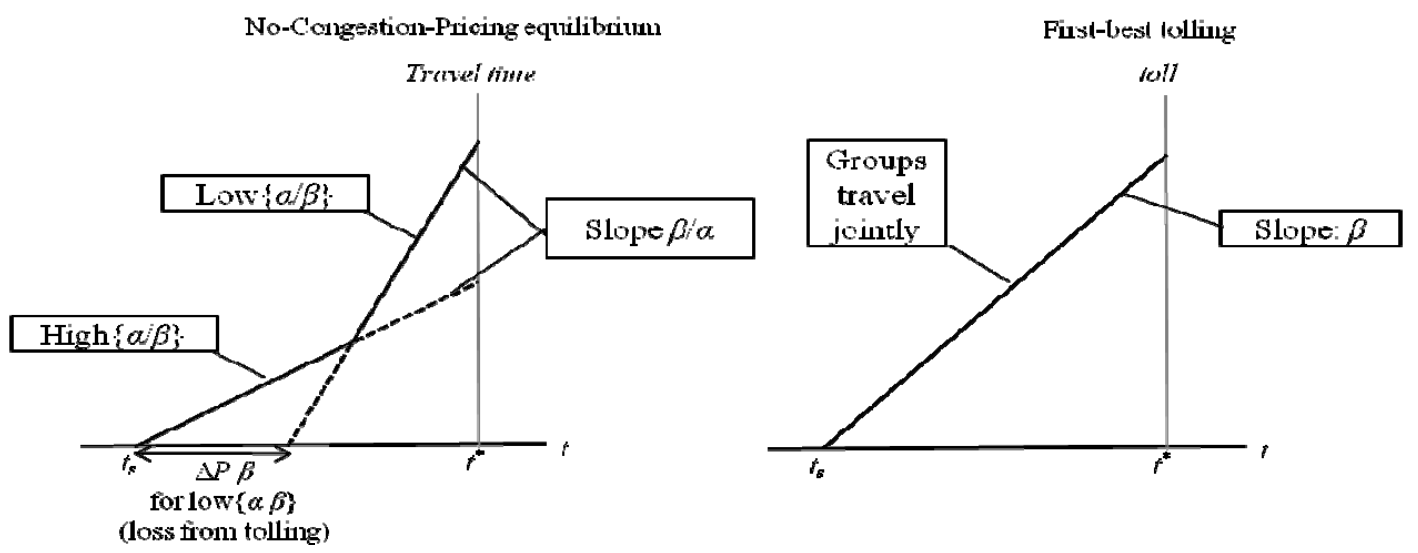

The price as a function of the arrival time $t$ includes travel-time costs $\left(C_{T}[i, t]\right)$, scheduling costs $\left(C_{S D}[t]\right)$, and possibly a toll $\left(\tau^{c}[t]\right.$ ) (we use superscript $c$ to indicate the car, the train levy will be indicated by $\rho^{t}$ ). Observing that the price for a user equals the schedule delay when its group iso-price line intersects the horizontal axis, we can determine the following prices (where subscript $L$ indicates the Low group, and $H$ the High group. 


$$
\begin{aligned}
& P_{L}^{N C P}=C_{T}[i, t]+C_{S D}[t]=\beta \cdot \frac{n_{L}^{c}+n_{H}^{c} \cdot \mu_{L} / \mu_{H}}{s}=\beta \cdot \frac{n_{L}^{c}+n_{H}^{c} \cdot \alpha_{L} / \alpha_{H}}{s}, \\
& P_{H}^{N C P}=C_{T}[i, t]+C_{S D}[t]=\beta \cdot \frac{n_{L}^{c}+n_{H}^{c}}{s}, \\
& P_{L}^{F B}=C_{S D}[t]+\tau^{c}[t]=\beta \cdot \frac{n_{L}^{c}+n_{H}^{c}}{s}, \\
& P_{H}^{F B}=C_{S D}[t]+\tau^{c}[t]=\beta \cdot \frac{n_{L}^{c}+n_{H}^{c}}{s} .
\end{aligned}
$$

Here, $n_{i}^{c}$ is the number of drivers of group $i$. The total number of drivers is $N^{c}$. The capacity of the bottleneck is $s$.

Without heterogeneity, the price would be $\beta \cdot N^{c} / s$ for all drivers in both regimes. Hence, ratio heterogeneity does not affect the price of the High group; but does lower the NCP price for the Low group. The high $\mu_{H}$ means that High users build up the queue more slowly than Low users would, lowering the price for Low users compared with homogeneous users. This also means that the High users impose lower externalities than Low users: the ratio of marginal effects being $\left(\partial P_{L}^{N C P} / \partial n_{H}^{c}\right) /\left(\partial P_{L}^{N C P} / \partial n_{L}^{c}\right)=\alpha_{L} / \alpha_{H}$ (see Lindsey, 2004). This, in turn, means that the weighted average of the marginal external costs is lower with ratio heterogeneity than with homogeneity.

With first-best pricing, the price is $\beta \cdot N^{c} / s$ for both groups. Hence, tolling does not affect the price of the High group, but raises it for the Low group by $\Delta P=\left(1-\alpha_{L} / \alpha_{H}\right) \beta \cdot n_{H}^{c} / s$. Combining this with the fact that ratio heterogeneity does not affect the FB toll revenue this implies that tolling is less welfare increasing with ratio heterogeneity than with homogeneity, where prices are unaffected by tolling. With two groups, more heterogeneity means that the ratio $\alpha_{L} / \alpha_{H}$ is higher (while keeping the average values fixed). With more heterogeneity, congestion externalities are lower, and tolling raises the price for the Low group more.

Arnott, de Palma and Lindsey (1988; 1994) and de Palma and Lindsey (2002) consider cases with many groups and fixed demand. Their results are consistent with the foregoing discussion. Without tolling, users arrive in order of decreasing ratio $\mu_{i} \equiv \alpha_{i} / \beta$. The price for a group increases with $\mu_{i}$. With first-best pricing, all groups travel jointly and face the same price of $\beta \cdot N^{c} / s$. All users lose due to first-best pricing, except the users with the highest values, who are unaffected.

Van den Berg and Verhoef (2011b) show that price sensitivity of demand changes things. Users with low ratios $\mu_{i}$ decrease their demand when pricing is introduced in response to their increased price. This lowers congestion, making tolling beneficial for users with high ratios. Under continuous heterogeneity, more ratio heterogeneity again has the same effects as in the 
discrete case. ${ }^{5}$ Moreover, they find that the relative efficiency of tolling one of two parallel bottlenecks also decreases with the degree of ratio heterogeneity.

These results differ from what Small and Yan (2001) and Verhoef and Small (2004) find. They use static flow congestion and two parallel links, and find that the gain of first-best pricing and the relative efficiency of single-link tolling increase with the amount of heterogeneity in the value of time. Their result is due to self-sorting by link. Drivers with high values of time use the link with the shorter travel time but higher monetary cost, making the shorter travel time of this link more valuable. Drivers with low values use the link with the longer travel time, making its extra travel time less costly. Clearly, the type of congestion hence also influences how heterogeneity affects tolling.

Following Van den Berg and Verhoef (2011b), we can generalise the equilibrium price in (2) for when the value of time is continuously distributed:

$$
P_{i}^{N C P}=C_{S D}[t]+C_{T}[i, t]=\frac{\beta}{s} N^{c}\left(F^{c}\left[\alpha_{i}\right]+\alpha_{i} \int_{\alpha_{i}}^{\bar{\alpha}} \frac{f^{c}\left[\alpha_{j}\right]}{\alpha_{j}} d \alpha_{j}\right) .
$$

The distribution of car users follows the probability density function $f^{c}\left[\alpha_{i}\right]$. The cumulative distribution function is $F^{c}\left[\alpha_{i}\right]$. The maximum value of time is denoted $\bar{\alpha}$. Scheduling costs for drivers of type $i$ equal the left term between round brackets, $F^{c}\left[\alpha_{i}\right]$, multiplied by the term outside them: $C_{S D}[t]=\beta \cdot N^{c} \cdot F^{c}\left[\alpha_{i}\right] / s^{c}$. Queuing costs are the right term in round brackets multiplied by the term outside then. Again, users with a certain $\mu_{i}$ gain when some users with a higher $\mu_{j} \equiv \alpha_{j} / \beta$ are replaced by users with an even higher $\mu_{k}$, but do not suffer if some users with a lower $\mu_{j}$ are replaced by users who have an even lower $\mu_{k}$. It is this asymmetry that causes total costs to decrease with an increase in the degree of ratio heterogeneity.

With first-best (FB) tolling, users arrive in order of increasing value of schedule delay. However, as this value is the same for all, the order is undetermined, and the FB price in (4) is the same for all users. Here, $N^{c}$ is the endogenous number of drivers in the FB equilibrium. Since tolling affects users with different values of time differently, it also alters the distribution of users.

$$
P_{i}^{F B}=C_{S D}[t]+\tau^{c}[t]=\beta \cdot N^{c} / s
$$

Second-best road pricing, with unpriced crowding in the train, uses the same formula for the time-variant part of the toll as the FB toll, but adds a time-invariant part. With welfare

\footnotetext{
${ }^{5}$ Under continuous heterogeneity, we define an increase in the heterogeneity as an increasing variance of the distribution while the mean remains the same. More heterogeneity could result from more users in the tails of the distribution or the highest and lowest values becoming more extreme.
} 
maximisation, the time-invariant part is negative to attract users away from the train (similar to what Braid (1996) finds for two parallel roads). With profit maximisation, the time-invariant term is positive and maximises toll revenue.

\subsection{Proportional heterogeneity and pricing of a single bottleneck}

The second type of heterogeneity that we consider concerns "proportional heterogeneity". Here, the ratio of values of time and schedule delay $\left(\alpha_{i} / \beta_{i}\right)$ is constant. But all values vary in fixed proportions, following the scalar $k_{i}: \alpha_{i} \equiv a \cdot k_{i}$ and $\beta_{i} \equiv b \cdot k_{i}$. Our road model is adapted from Van den Berg and Verhoef (2011a). This type of heterogeneity was introduced by Vickrey (1973), and it might be interpreted as stemming from income differences.

Figure 2: Example of proportional heterogeneity with two discrete groups

No-Congestion-Pricing equilibrium

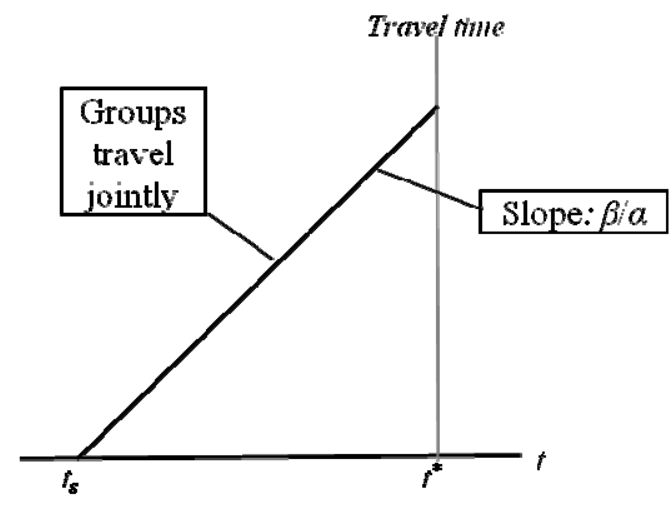

First-best tolling

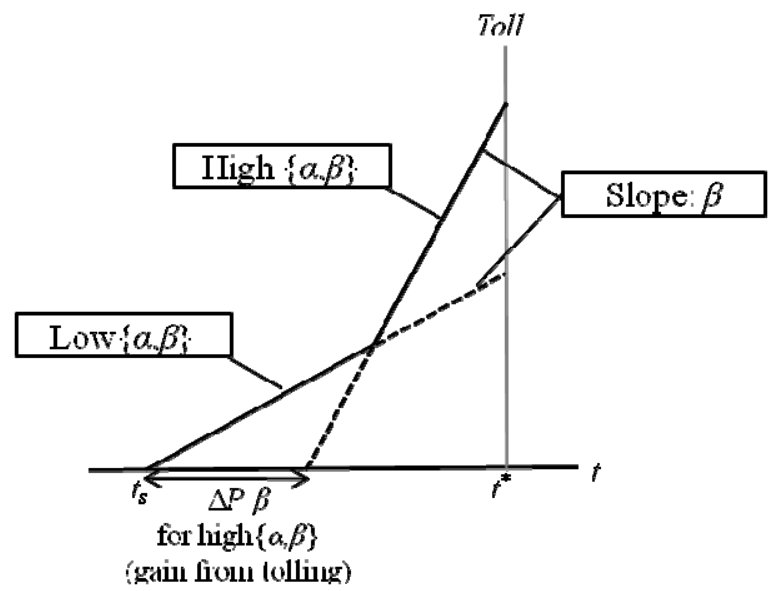

Figure 2 gives example NCP and FB equilibria for two groups of users and fixed demand. Now the groups travel jointly in the $\mathrm{NCP}$ case, since the slope of the iso-price line is $\beta / \alpha$, and this ratio is the same for all. First-best pricing again removes all queuing, and now High users-here defined as users with the high $\alpha$ and $\beta$-arrive closest to $t^{*}$, because they are most willing to pay a toll in order to reduce schedule delays. NCP and FB equilibria prices can again be written as the schedule delay cost at the moment that the relevant iso-price line intersects the horizontal axis:

$$
\begin{aligned}
& P_{L}^{N C P}=C_{S D}[i, t]+C_{T}[i, t]=\beta_{L} \cdot \frac{n_{L}^{C}+n_{H}^{C}}{s}, \\
& P_{H}^{N C P}=C_{S D}[i, t]+C_{T}[i, t]=\beta_{H} \cdot \frac{n_{L}^{C}+n_{H}^{C}}{s}, \\
& P_{L}^{F B}=C_{S D}[i, t]+\tau^{c}[t]=\beta_{L} \cdot \frac{n_{L}^{C}+n_{H}^{C}}{s},
\end{aligned}
$$




$$
P_{H}^{F B}=C_{S D}[i, t]+\tau^{c}[t]=\frac{\beta_{L} \cdot n_{L}^{C}+\beta_{H} \cdot n_{H}^{C}}{s}
$$

The High group gains from tolling, because this group shifts to a lower iso-price curve: the intersection of its iso-price curve with the horizontal axis is closer to $t^{*}$ in the right panel than in the left panel. For the Low group the price remains the same. The High group gains because users with low values require a less steep toll schedule to prevent queuing - the slope of the toll schedule being $\beta$ - and this lowers the tolls that users with high values will have to pay.

Vickrey (1973) showed that with continuous heterogeneity the same mechanisms apply. In the NCP equilibrium, the order of users is undefined. With FB pricing, users with the highest values arrive closest to $t^{*}$. Under fixed demand, users with the lowest values are unaffected by tolling, while all other users gain - and more so, the higher their values are. Tolling makes the arrival order more efficient: total scheduling costs decrease, because drivers with high values of schedule delay now arrive closets to $t^{*}$. Van den Berg and Verhoef (2011a) show that the gain from tolling increases with a means-preserving increase in the proportional heterogeneity, as the gain from the more efficient arrival ordering increases. Further, the relative efficiency of secondbest tolling of only one of two parallel bottlenecks also increases. With more heterogeneity, paylane users with high values have higher mean values of time and schedule delay, making the travel time and schedule delay savings that the pay-lane offers more valuable.

With continuous heterogeneity and no tolling, the NCP prices generalise to

$$
P_{i}^{N C P}=C_{S D}[i, t]+C_{T}[i, t]=\beta_{i} \cdot N^{c} / s
$$

The FB prices are

$$
P_{i}^{F B}=C_{S D}[i, t]+\tau^{c}[t]=\frac{N^{c}}{s}\left(\beta_{i}\left(1-F^{c}\left[\beta_{i}\right]\right)+\int_{\underline{\beta}}^{\beta_{i}} \beta_{j} f^{c}\left[\beta_{j}\right] d \beta_{i}\right)
$$

The distribution of users in the FB equilibrium follows the probability density function $f^{c}\left[\beta_{i}\right]$; the cumulative distribution function is $F^{c}\left[\beta_{i}\right]$. This distribution is endogenous: it depends on the tolling policy, and on the price sensitivity of each type of user. Although the equation might look tedious, it is entirely consistent with $(5 \mathrm{c}, \mathrm{d})$. Again users with a lower $\beta_{j}$ than $\beta_{i}$ impose a lower price increase on a type $i$ user than users with a higher or equal $\beta_{j}{ }^{6}$

\footnotetext{
${ }^{6}$ Section 3 of Arnott et al. $(1988,1994)$ has independent heterogeneity in values of time and schedule delay. In our terminology, this means that they consider a mix of proportional and ratio heterogeneity. This explains their finding that the welfare gain of tolling can be higher or lower with heterogeneity than with homogeneity: it depends on the relative degrees of proportional heterogeneity — which raises the gain—and ratio heterogeneity, which lowers the gain. Sections 4 and 5 of Arnott et al. (1988,
} 


\section{Analytical rail model}

With the road side described, we now turn to the train. Congestion in public transport can take many forms, including crowding in the train, longer times to board and leave the train, and queuing on the platform to enter a train for several headways between services. We prefer crowding congestion. Boarding and leaving times are short relative to total travel time, and thus their costs seem minor. Queuing at the train platform for several headways between services appears rare. Conversely, crowded trains are indeed an often mentioned discomfort.

In the crowding model of Kraus (1991), the value of travel time is higher for standing than for seated passengers. Yet, crowding cost may also depend directly on the number of users: it is more unpleasant to sit or stand in a fully packed train than in a half-full train. The meta study for the UK of Wardman and Whelan (2011) confirms this. When all seats are taken, the most supported function is a value of time that increases linearly with the number of users. When there are empty seats, the value of time seems constant when most seats are empty; when many seats are taken, some studies find that the value of time increases with the number of users. Li and Hensher (2011) review international empirical studies. They find three types of crowding cost functions in the literature: (1) crowding increases the value of time (so this set-up follows the one in Wardman and Whelan (2011)), (2) a separate per minute monetary value of crowding, and (3) a separate per trip monetary value of crowding. Consistent with case (1), Wu and Huang (2010) and Rouwendal and Verhoef (2004) use a value of time that increases with the number of users due to crowding. Instead, Huang (2000) follows cases (2) and (3) (which are equivalent as the travel time is constant), and has separate crowding and travel time costs. Crowding costs are linear in the number users, and the distinction between standing and seated passengers is ignored. This paper follows Huang's set-up.

The analytical models ignore travel time and the train fare that covers the marginal operating costs, as they are assumed to be constant over time. The numerical models will include these.

\subsection{Ratio heterogeneity and rail pricing}

Since $\beta$ is generic with ratio heterogeneity, there is no product differentiation or self-selection over time in the train (recall that that train travel times are constant). The price for a user must be the same in all used train services. We assume that it is impossible to arrive after $t^{*}$. We denote the train that arrives at $t^{*}$ as Service 1; earlier services have a higher index. So, a service is a particular scheduled train. The headway between train services is given, and equals $h$. The price

1994) analyse, respectively, heterogeneity in the ratio of value of schedule delay early and late and in the preferred arrival times. This paper focuses on the two types of heterogeneity in Section 3 of Arnott et al. (1988, 1994). 
of service $r$ is the sum of crowding cost $\left(C_{C R}[r]\right)$, scheduling costs $\left(C_{S D}[r]\right)$, and a possible crowding levy. The price is independent of the value of time. Crowding costs in service $r$ are $g \cdot N_{r}^{t}$; scheduling costs are $h(r-1) \beta$. The $g$ is the crowding coefficient, $N_{r}^{t}$ is the number of users in service $r$.

Figure 3 shows how crowding costs should vary per service to make all services equally attractive to use. Because Services 7 and 8 would need negative crowding costs, they will not be used, and Service 6 is the earliest service to be used. It has the highest scheduling costs and the lowest number of users and crowding cost. To make difference in crowding cost, $g \cdot\left(N_{j}^{t}-N_{j-1}^{t}\right)$, balance difference in scheduling cost, $\beta \cdot h$, the difference in numbers of users between two successive services $j$ and $j+1$ should satisfy $N_{j}^{t}-N_{j-1}^{t}=\beta \cdot h / g$. Accordingly, crowding costs increase linearly over time, which is what the black trend line in Figure 3 indicates.

The earliest service to be used will be indicated as $R$. Note that $R$ is not a policy instrument in our setting; it is determined by a user equilibrium condition. There might be earlier services that are unused, such as services 7 and 8 in Figure 3. Since by assumption the provision of services is costless, these empty services do not harm welfare or profits.

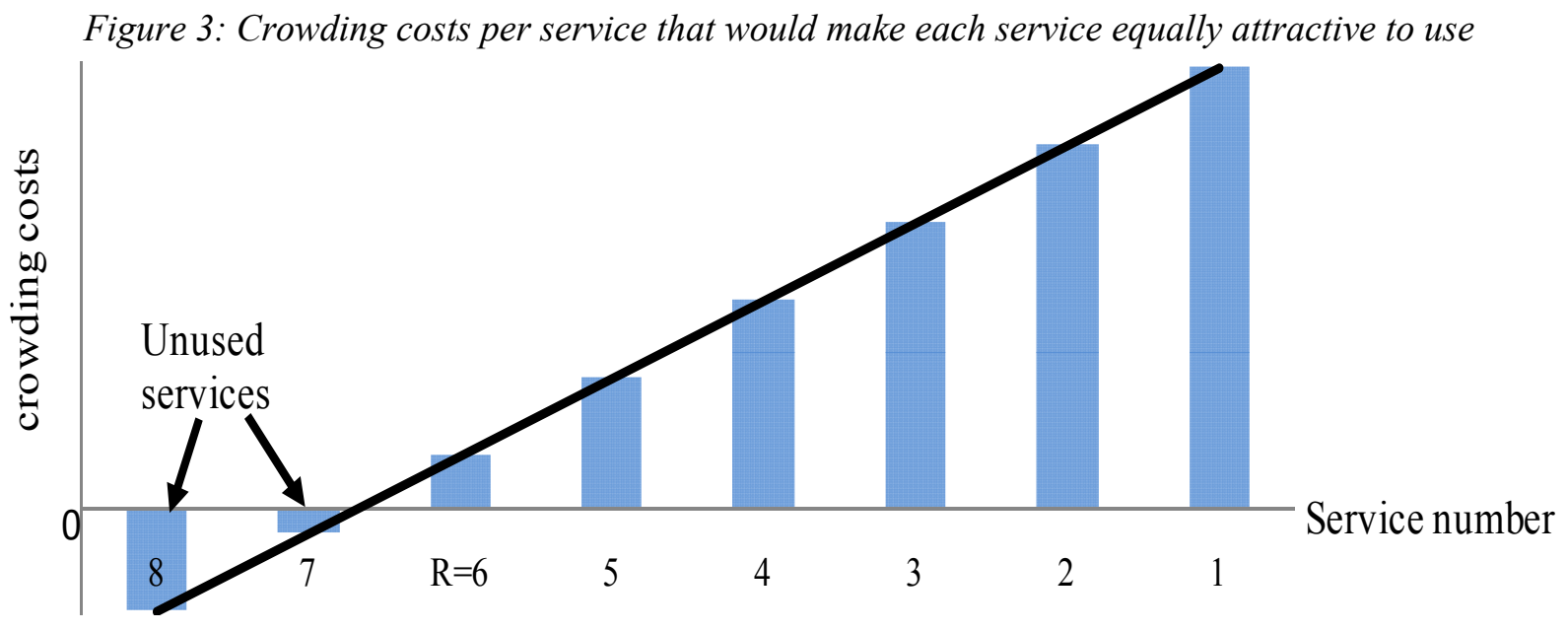

Knowing how $N_{r}^{t}$ varies between services, we can write the total number of users as ${ }^{7}$

$$
\begin{aligned}
N^{t} & =\sum_{1}^{R} N_{r}^{t}=N_{1}^{t}+\left(N_{1}^{t}-\beta \cdot h / g\right)+\left(N_{1}^{t}-2 \beta \cdot h / g\right)+\ldots+\left(N_{1}^{t}-(R-1) \beta \cdot h / g\right), \\
& =N_{1}^{t} \cdot R-(1+2+\ldots+(R-1)) \beta \cdot h / g=N_{1}^{t} \cdot R-((R-1) R / 2) \beta \cdot h / g
\end{aligned}
$$

which implies that the number of users in service 1 is

\footnotetext{
${ }^{7}$ The substitution of $R(R-1) / 2$ for the series $(1+2+\ldots+R-1)$ follows Kraus and Yoshida (2002).
} 


$$
N_{1}^{t}=N^{t} / R+((R-1) / 2) \beta \cdot h / g .
$$

To find $R$, we first calculate for which arrival time the scheduling costs would equal the crowding costs of service 1 . Since the number of services used is an integer, there is generally no service that arrives at this moment. Service $R$ is then the first service to arrive after this time. Hence, $R$ depends on $N^{t}$ and on the cost parameters in the following way:

$$
R=\text { Floor }\left[\frac{g \cdot N_{1}^{t}}{\beta \cdot h}\right]=\text { Floor }\left[\frac{1}{2}+\frac{\sqrt{8 g \cdot N^{t}+\beta \cdot h}}{2 \sqrt{\beta \cdot h}}\right] \text {, }
$$

where Floor $[x]$ denotes the highest integer below $x$. The second expression for $R$ in (9) is obtained by substituting (8) into the first one and rewriting. We can next derive the NCP price for Service 1 by inserting (8) and (9) into the crowding cost function. This price is also the equilibrium price for all services, since prices are constant over time:

$$
P_{i}^{N C P}=C_{C R}[r]+C_{S D}[r]=g \cdot N_{r}^{t}+h(r-1) \beta=g \cdot N^{t} / R-\beta \cdot h(R-1) / 2 .
$$

Although the price is the same in all used services, marginal social cost is not. The marginal external crowding cost in service $r$ is $g \cdot N_{r}^{t}$. Service 1 has the highest externalities, service $R$ the lowest. We find it convenient to separate the train ticket price into two components: a train "fare" that equals marginal operating costs, and a time-varying "levy", $\rho_{r}^{t}$, that is used to manage the crowding externalities. In first-best optimum, the levy equals marginal external crowding cost. Excluding fixed travel-time cost and marginal operating cost, the FB price is the sum of crowding cost, crowding levies, and scheduling cost:

$$
P_{i}^{F B}=C_{C R}[r]+C_{S D}[r]+\rho_{r}^{t}[r]=2 g \cdot N^{t} / R-\beta \cdot h(R-1) / 2
$$

The new user-equilibrium $R$ differs from in (9) due to the internalisation of the externalities:

$$
R=\text { Floor }\left[\frac{1}{2}+\frac{\sqrt{16 g \cdot N^{t}+\beta \cdot h}}{2 \sqrt{\beta \cdot h}}\right]
$$

The $N^{t}$ is different in the NCP and FB equilibria, as the number of users is endogenous and prices differ. 
If road congestion is not priced, we are in a second-best situation. Then, the welfaremaximising time-invariant part of the levy can be expected to be negative (i.e. a subsidy). This reduces the number of car drivers, which increases welfare as marginal social cost on the road exceeds the private cost. In contrast, a private operator is likely to add a positive time-invariant term to maximise its profits. With FB pricing of both modes, there is no extra time-invariant addition to the levy, as the time-variant levy equals the marginal externality.

Pricing of crowding externalities increases the prices of train travel. This differs from bottleneck congestion, where tolling may lower the price for drivers with a high ratio $\mu_{i} \equiv \alpha_{i} / \beta$. But, even with homogeneous users, differences persist: FB pricing of a bottleneck would leave the price unchanged, as the queuing is a pure loss (Vickrey, 1969); with crowding congestion or dynamic flow congestion as in Chu (1995), there is no pure loss and FB pricing raises the price.

\subsection{Proportional heterogeneity and rail pricing}

We have just established that ratio heterogeneity has little impact in our train model, since travel time is fixed. With proportional heterogeneity, the $\alpha_{i}$ and $\beta_{i}$ vary proportionally over users, and we can expect a greater impact. Users with the highest values use Service 1 and arrive at $t^{*}$, as they care most about schedule delays. Users with the lowest values use service $R$. Consequently, even without congestion pricing, users arrive ordered by increasing $\beta$, while on the road this only happens with pricing. This self-ordering lowers the mean scheduling cost and thereby the mean price, and more so for more pronounced heterogeneity. This also puts an upward pressure on the number of used train services, as the earliest services are used by users with the lowest values of schedule delay, who are more willing to avoid crowding cost by taking an earlier train.

Figure 4: Crowding costs per service that would make each service attractive to use

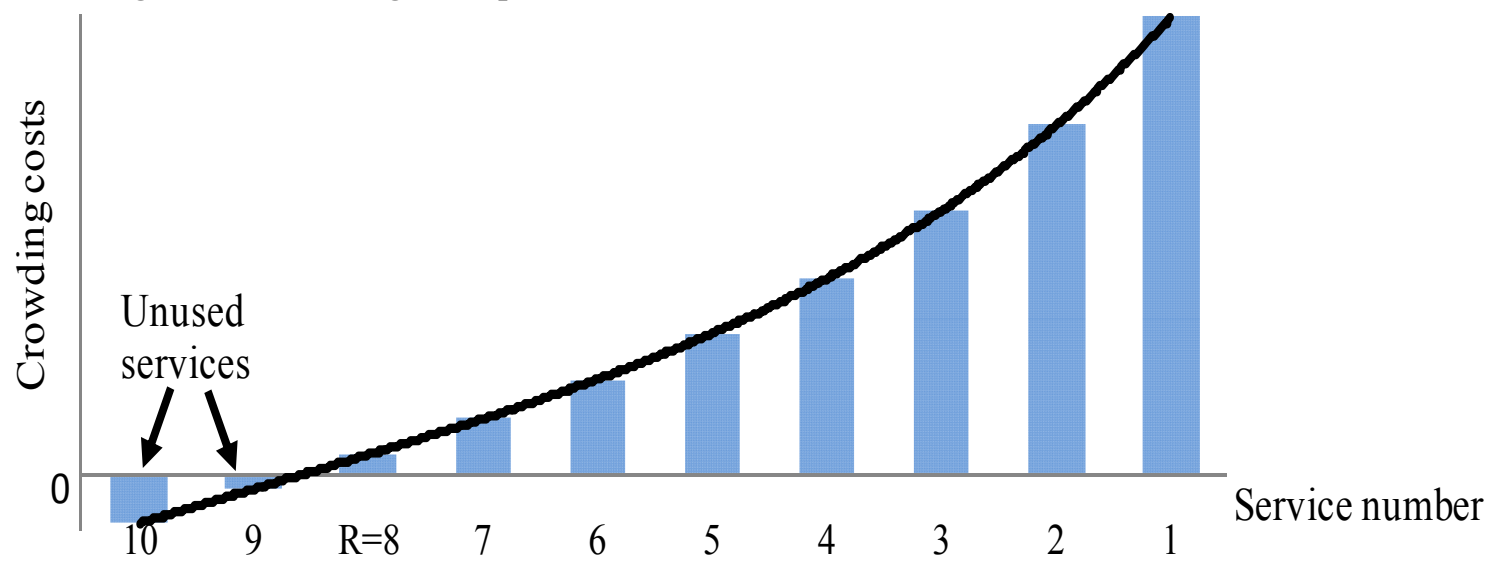

Crowding costs now change non-linearly over time, as shown by the trend curve in Figure 4, since users travel separated by value of schedule delay. A consequence of this is that we are 
unable to find closed-form solutions for the number of users per run and the number of services used. But we can find numerical solutions. In particular, for each pair of services $r$ and $r+1$ there is a value of schedule delay that implies indifference between the two. Using these indifferent users it is possible to numerically solve the model. Rail-travel prices are now

$$
P_{i}^{N C G}=C_{C}[r]+C_{S D}\left[r, \beta_{i}\right]=g \cdot N_{r}^{t}+h(r-1) \beta_{i}
$$

Crowding externalities are not affected by proportional heterogeneity, and hence service $r$ 's crowding levy still follows $g \cdot N_{r}^{t}$. The FB price is

$$
P_{i}^{F B}=C_{C}[r]+C_{S D}\left[r, \beta_{i}\right]+\rho_{r}^{t}[r]=g N_{r}^{t}+h(r-1) \beta_{i}+g N_{r}^{t}
$$

\section{Set-up numerical models}

We now discuss the calibration of the model. The NCP equilibrium is calibrated such that there are 9000 road users and 5000 train users. The bottleneck capacity is 4500 cars per hour; hence the road peak lasts 2 hours. The crowding coefficient, $g$, is $1 / 200$. The fixed headway, $h$, between trains is 15 minutes. The mean value of time is $€ 10.50$. Free-flow car-travel time is 30 minutes. Fixed train-travel time is 45 minutes. The operating costs of the car are $€ 6.50$. The rail fare equals per-user operating costs of $€ 7.50$. The fixed costs for the rail operator are zero, although Section 7 has a sensitivity analysis of the effect of fixed cost.

The average value of schedule delay is $€ 5.00$. In the base-case parameterisation of proportional heterogeneity, the NCP equilibrium has a value of schedule delay that is uniformly distributed between $€ 2.00$ and $€ 8.00$, and the value of time is 2.1 times the value of schedule delay. With ratio heterogeneity, the value of time ranges between $€ 5.50$ and $€ 15.50$, and the value of schedule delay is $€ 5.00$. Without congestion pricing, the distribution of users on the road and rail are calibrated to follow the same density function. Pricing changes the prices, and thus results in different distributions for the modes.

Finally, the models are calibrated so that the weighted average of the own-price elasticity, in the NCP equilibrium, is -0.5 for both car and train; the cross-elasticity of rail-travel demand with respect to the price of car travel is $0.1 .^{8}$

\footnotetext{
${ }^{8}$ To achieve these goals, we adapt the calibration procedure of Van den Berg and Verhoef (2011a,b). The constant of the inverse demand in eq. (1) for mode $j$ for type $i$ is $P_{i j}^{N C G}-E_{j} \cdot N_{k}-B_{j} \cdot N_{j}$, where $P_{i j}^{N C G}$ is the NCP price. To ensure the distribution of users, $b_{i j}$ and $e_{i j}$ equal the NCP distribution function of users. Finally, we set $B_{j}, B_{k}$, and $E_{j}=E_{k}$ such that the desired equilibrium elasticities result.
} 


\section{Numerical pricing model with proportional heterogeneity}

We study a number of policies, which are summarised in Table 1. In the NCP regime, there is no congestion pricing and the rail fare equals marginal operating cost. In all regimes, we allow for time variation of the toll. With second-best road pricing, it is convenient to decompose the toll into a time-variant component - which eliminates the queuing - and a time-invariant term. With welfare maximisation by "pricing the road only" (CW), we find that this second term is negative to attract users away from the suboptimally priced train. With "profit maximisation on the road only" (CP), the term is positive to extract more revenues. The second-best schemes train-welfare (TW) and train-profit (TP) maximisation have similar set-ups. ${ }^{9}$ Finally, with first-best (FB) pricing, the road toll prices congestion externalities; the train has a levy that equals the crowding externalities plus a fare that equals marginal operating cost. Because we are unable to find closed-form solutions for the regimes, we present numerical results for the base-case parameterisation and sensitivity analyses that explore the effects of heterogeneity.

Table 1: Description of the pricing regimes

\begin{tabular}{|c|c|c|c|}
\hline Policy & Meaning & Rail pricing & Road Pricing \\
\hline NCP & No Congestion Pricing & Only a fare that equals marginal rail operating cost $\left(v^{t}\right)$ & No-toll \\
\hline TW & Train Welfare & $\begin{array}{l}\text { Welfare-maximising second-best congestion levy }+ \\
\text { a fare that equals marginal-rail-operating cost }\end{array}$ & No-toll \\
\hline TP & Train Profit & $\begin{array}{l}\text { Rail-profit-maximising second-best congestion levy }+ \\
\text { a fare that equals marginal-rail-operating cost }\end{array}$ & No-toll \\
\hline $\mathrm{CW}$ & Car Welfare & Only a fare that equals marginal-rail-operating cost & $\begin{array}{l}\text { Welfare-maximising second- } \\
\text { best congestion tolling }\end{array}$ \\
\hline $\mathrm{CP}$ & Car Profit & Only a fare that equals marginal-rail-operating cost & $\begin{array}{l}\text { Road-profit-maximising } \\
\text { second-best congestion tolling }\end{array}$ \\
\hline FB & First-best & $\begin{array}{c}\text { First-best congestion levy }+ \text { a fare that equals marginal- } \\
\text { rail-operating cost }\end{array}$ & First-best congestion toll \\
\hline
\end{tabular}

Figure 5: Prices in the NCP equilibrium including monetary costs and free-flow travel time

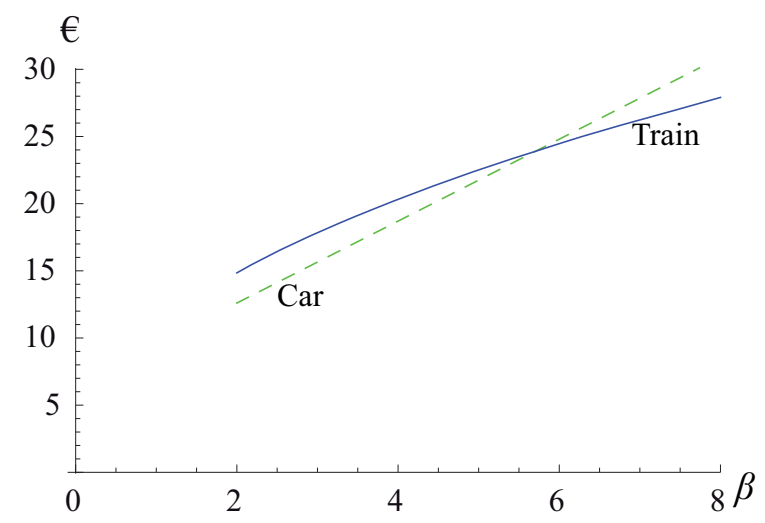

\footnotetext{
${ }^{9}$ So we do not study alternative objectives for the rail operator, such that it maximises welfare under a minimum profit constraint, or that it maximises profit, but faces fare or maximum profit regulations.
} 


\subsection{Base case no-congestion-pricing (NCP) equilibrium}

This section discusses the pricing regimes from Table 1 with proportional heterogeneity. Section 6 will consider the same regimes under ratio heterogeneity. Figure 5 shows the NCP prices by $\beta$ including monetary costs and free-flow travel time. The price of train travel is increasing in $\beta$ and piecewise linear with kinks at the values that imply indifference between two services; however, these kinks are hard to detect visually. Users to the left and right of a kink thus use different services. For all users in service 1, the price excluding travel-time cost is the same. Prices of car travel increase linearly with $\beta$, consistent with equation (6). Because the two modes are imperfect substitutes, they are used by users with all values of time and schedule delay.

\subsection{Congestion pricing and proportional heterogeneity}

Table 2 shows the aggregate results of the different policies. The $\mathrm{CW}$ only prices the road and attains $95.8 \%$ of the first-best gain, while TW only prices the train and attains only $3.4 \%$. Road tolling lowers prices; rail levying increases prices. A first reason for these differences is that the average NCP externality on the road is $€ 10.00$, whereas in the train it is $€ 6.04$. The lower externality is partly due to the lower number of train users. Yet, the main difference between bottleneck and crowding pricing is that bottleneck congestion has a pure waste from queuing, and tolling removes this, while for the train not all congestion is a pure loss. Therefore, externality pricing is more beneficial for society in the bottleneck model than in the crowding model.

Table 2: Base case effects of the policies with proportional heterogeneity

\begin{tabular}{lcccccc}
\hline & NCP & TW & TP & CW & CP & FB \\
\hline Time-invariant train levy & - & $-€ 2.97$ & $€ 22.65$ & - & - & - \\
Time-invariant road toll & - & - & - & $-€ 0.63$ & $€ 24.51$ & - \\
Mean car-travel price $\left(\mathrm{E}\left[P^{C}\right]\right)$ & $€ 21.75$ & $€ 21.75$ & $€ 22.55$ & $€ 19.70$ & $€ 41.14$ & $€ 20.32$ \\
Mean train-travel price $\left(\mathrm{E}\left[P^{t}\right]\right)$ & $€ 22.15$ & $€ 21.98$ & $€ 44.79$ & $€ 22.04$ & $€ 22.55$ & $€ 24.54$ \\
Total toll revenue & - & - & - & $€ 34,284$ & $€ 136,059$ & $€ 40,062$ \\
Total crowding levy revenue & - & $€ 1,232$ & $€ 61,783$ & - & - & $€ 14,394$ \\
Consumer Surplus & $€ 414,073$ & $€ 414,788$ & $€ 321,672$ & $€ 434,714$ & $€ 277,826$ & $€ 416,803$ \\
Welfare & $€ 414,073$ & $€ 416,020$ & $€ 383,455$ & $€ 468,997$ & $€ 413,885$ & $€ 471,259$ \\
Number of car driver $\left(N^{c}\right)$ & 9000 & 8995.6 & $9,747.6$ & 9447.1 & 5065.7 & 9423.8 \\
Number of train users $\left(N^{t}\right)$ & 5000 & 5014.7 & $2,479.9$ & 4918.7 & 5724.0 & 4656.8 \\
Relative efficiency & 0 & 0.034 & -0.535 & 0.958 & -0.003 & 1 \\
Percentage welfare gain & - & $0.47 \%$ & $-7.39 \%$ & $13.26 \%$ & $-0.05 \%$ & $13.81 \%$ \\
Percentage of NCP users & who & & & & & \\
would be better off & - & $81.4 \%$ & $0 \%$ & $100 \%$ & $0 \%$ & $49.5 \%$ \\
\hline
\end{tabular}

Figure 6 shows the change in prices of train travel due to the policies compared to the NCP equilibrium. Figure 7 does this for car travel. In both figures, the right panel is for profit 
maximisation to allow for differences in scale due to profit maximisation. The higher $\beta$ is, the more the price of train travel increases due to congestion pricing. These users use services that

arrive closer to $t^{*}$, which have higher crowding costs and thus higher levies. The curves showing the change in the price of train travel due to rail pricing are piecewise linear with upward sloping sections followed by flat sections. The flat sections represent sets of users who use the same service as before: for them only crowding costs and congestion levies change, which they value equally. The sloping sections are for switchers, for whom scheduling costs increase, which depend on $\beta$. All users with low values of time and schedule delay switch services, since they care relatively little about schedule delays and more about congestion levies.

The second-best TW scheme only prices rail users. It is less harmful for train users than the first-best (FB) policy, because it adds a subsidy to the time-variant congestion levy to attract road users. In fact, the TW lowers the prices of train travel for values of schedule delay below $€ 4.85$. These users arrive far from $t^{*}$, in relatively empty trains, where the sum of time-variant and timeinvariant parts of the levy is negative.

Road pricing is more likely to be regressive: the higher $\alpha$ and $\beta$ are, the higher the gain from pricing. In contrast, the price change for rail travel increases with $\beta$, which suggest that rail pricing might be progressive. This indicates that congestion pricing might have a very different political acceptability in different modes.

\subsection{Sensitivity analysis on the amount of proportional heterogeneity}

Figure 6 and 7 suggest that heterogeneity matters. A natural follow up question is how sensitive the results are with respect to the degree of heterogeneity, which we measure by the spread of the uniform distribution of the value of schedule $(\beta)$, which also determines the spread of the value of time, because of the fixed proportions. Without congestion pricing, the average price for car travel is unaffected by the spread, as also implied by equation (6). The mean price of train travel decreases with the spread due to the self-ordering of users: train users with higher values arrive closer to $t^{*}$ when delays are low; the opposite holds for users with low values.

Table 3 shows consumer surplus and prices in the NCP equilibria for distributions with spreads of $0,3,5,6$, and 7. A spread of 0 means homogeneous users. All distributions of $\beta$ have a mean of $€ 5.00$. Consumer surplus decreases with the spread, but this is a result of the calibration, it does not reflect a meaningful effect of heterogeneity. 
Figure 6: Change in train-travel prices due to the implementation of pricing regimes
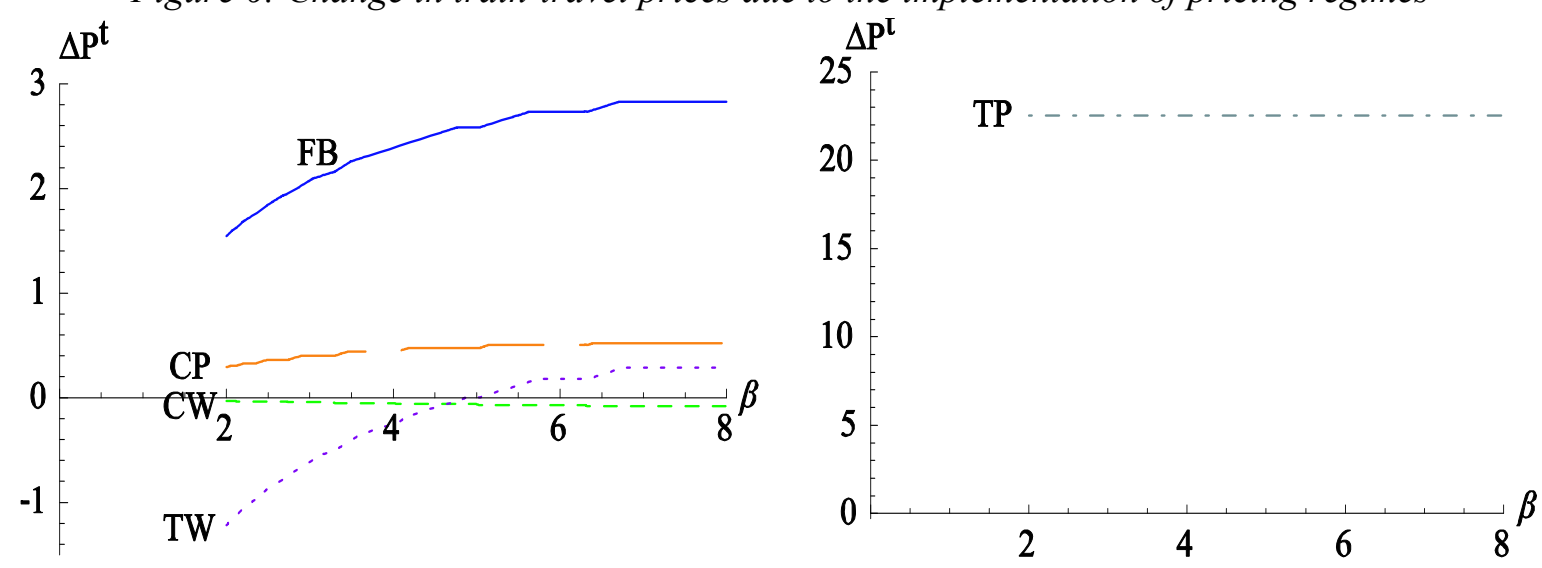

Figure 7: Change in car-travel prices due to the implementation of pricing regimes
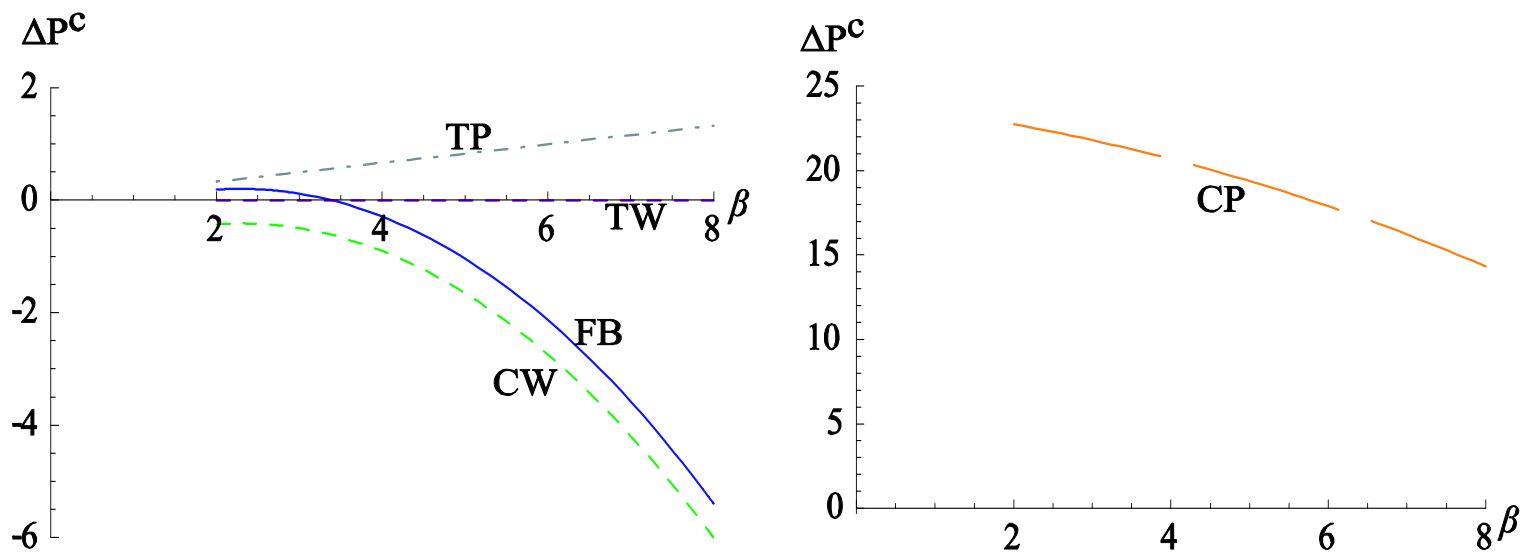

Table 3: Proportional heterogeneity and the no-congestion-pricing (NCP) case

\begin{tabular}{lccc}
\hline Spread of the value of schedule delay & Consumer surplus & $\mathrm{E}\left[P^{C}\right]$ & $\mathrm{E}\left[P^{t}\right]$ \\
\hline 0 & $€ 418,250$ & $€ 21.75$ & $€ 23.19$ \\
3 & $€ 416,241$ & $€ 21.75$ & $€ 22.69$ \\
5 & $€ 414,814$ & $€ 21.75$ & $€ 22.34$ \\
6 (Base case) & $€ 414,073$ & $€ 21.75$ & $€ 22.15$ \\
7 & $€ 413,260$ & $€ 21.75$ & $€ 21.94$ \\
\hline
\end{tabular}

Table 4 gives the results of FB pricing for different amounts of heterogeneity. FB prices of car travel decrease, and welfare increases, with the degree of proportional heterogeneity, because the gain from the more efficient arrival order increases. This is consistent with the single mode case (see Van den Berg and Verhoef, 2011a). The FB price of train travel also decreases with the spread. This is partly because the ordering on $\beta$ reduces scheduling cost; and the larger the spread is, the larger the reduction. Another reason is that road tolling lowers the average price of car travel, thereby lowering demand for train travel. 
Table 4: Heterogeneity in the value of schedule delay and first-best FB pricing

\begin{tabular}{lccccccccc}
\hline $\begin{array}{l}\text { Spread of the value } \\
\text { of schedule delay }\end{array}$ & $\mathrm{E}\left[P^{C}\right]$ & $\mathrm{E}\left[P^{t}\right]$ & Surplus & revenue & revenue & Welfare & $\% \Delta W$ & $N^{c}$ & $N^{t}$ \\
\hline 3 & $€ 21.06$ & $€ 25.39$ & $€ 409,819$ & $€ 43,004$ & $€ 15,708$ & $€ 468,531$ & $12.6 \%$ & 9258 & 4672 \\
5 & $€ 20.56$ & $€ 24.84$ & $€ 414,433$ & $€ 41,046$ & $€ 14,842$ & $€ 470,321$ & $13.4 \%$ & 9369 & 4662 \\
6 (Base case) & $€ 20.32$ & $€ 24.54$ & $€ 416,803$ & $€ 40,062$ & $€ 14,394$ & $€ 471,259$ & $13.8 \%$ & 9424 & 4657 \\
7 & $€ 20.08$ & $€ 24.22$ & $€ 419,138$ & $€ 39,076$ & $€ 13,902$ & $€ 472,116$ & $14.2 \%$ & 9479 & 4651 \\
\hline
\end{tabular}

Table 5 gives percentage welfare gains for the other policies. Table 6 reports the corresponding relative efficiencies. The welfare gain of second-best $\mathrm{CW}$ road pricing increases with the spread. Still, its relative efficiency decreases slightly. This differs from the results with second-best pricing of two roads that are perfect substitutes in Van den Berg and Verhoef (2011a), where the relative efficiency increases with the degree of proportional heterogeneity. The difference lies in that train and car are imperfect substitutes. With perfect substitutes, users with the highest $\alpha$ and $\beta$ flock to the priced link, as it is most beneficial to them. With imperfect substitutes, the priced link is used by all values of time and schedule delay, even though for many values the unpriced link has a lower price, and tolling raises the car-travel price. Furthermore, with imperfect substitutes, there are also users with high values who continue to use the unpriced train, even though it has a higher price. These effects lower the relative efficiency; and, accordingly, for two modes, the relative efficiency of CW pricing decreases with the amount of proportional heterogeneity if the degree of substitutability is low enough.

\section{Table 5: Effect proportional heterogeneity on percentage welfare gains}

\begin{tabular}{lccccc}
\hline Spread of $\beta$ & TW & TP & CW & CP & FB \\
\hline 0 & $0.62 \%$ & $-7.41 \%$ & $11.01 \%$ & $-1.55 \%$ & $11.42 \%$ \\
3 & $0.50 \%$ & $-7.41 \%$ & $11.97 \%$ & $-0.87 \%$ & $12.56 \%$ \\
5 & $0.48 \%$ & $-7.40 \%$ & $12.85 \%$ & $-0.34 \%$ & $13.38 \%$ \\
6 & $0.47 \%$ & $-7.39 \%$ & $13.23 \%$ & $-0.05 \%$ & $13.81 \%$ \\
7 & $0.45 \%$ & $-7.39 \%$ & $13.57 \%$ & $0.25 \%$ & $14.24 \%$ \\
\hline
\end{tabular}

Table 6: Effect of proportional heterogeneity on relative efficiencies

\begin{tabular}{lcccc}
\hline Spread of $\beta$ & TW & TP & CW & CP \\
\hline 0 & 0.054 & -0.649 & 0.966 & -0.136 \\
3 & 0.040 & -0.590 & 0.963 & -0.069 \\
5 & 0.036 & -0.553 & 0.960 & -0.025 \\
6 (Base case) & 0.034 & -0.532 & 0.958 & -0.003 \\
7 & 0.032 & -0.519 & 0.953 & 0.017 \\
\hline
\end{tabular}

Conversely, the relative efficiency of private $\mathrm{CP}$ road pricing increases with proportional heterogeneity. The difference between the $\mathrm{CW}$ and $\mathrm{CP}$ arises because with profit maximisation the number of drivers drops substantially and primarily high-values drivers continue to use the road. Hence, the effect of the imperfect substitutes is less pronounced with profit maximisation. 
Moreover, more proportional heterogeneity increases the mean values of time and schedule delay on the private road, making its travel time and schedule delay savings more valuable. Finally, more heterogeneity lowers the prices of train travel, increasing the competition that the private road faces and thereby lowering the mark-up that the firm can ask.

The relative efficiency of private TP (rail-only) pricing increases with the spread. This occurs predominantly because the FB percentage gain increases, which makes the TP's welfare loss relatively smaller. TP's welfare gain only increases slightly. With a larger spread, the lowest values of schedule delay are lower. This enables users with low values to use earlier train services. This easier shift to earlier services limits the market power of the operator, inducing a lower time-invariant levy. TW second-best rail pricing is hardly affected by the heterogeneity.

\subsection{Conclusions on proportional heterogeneity}

Time-variant tolling on the road makes the arrival order more efficient by lowering scheduling costs. In the train, this extra efficiency gain does not occur, since users always arrive ordered by $\beta$. Due to the extra efficiency gain on the road, the welfare gain of first-best pricing increases with the degree of proportional heterogeneity. The relative efficiency of "welfare maximisation by only pricing the road", however, can decrease with proportional heterogeneity; whereas with two perfect substitute roads, this relative efficiency increases. Since crowding-congestion pricing does not alter the arrival order in the train, proportional heterogeneity has little effect on the relative performance of schemes that only price the train.

\section{Numerical pricing model with ratio heterogeneity}

We now turn to the case of "ratio heterogeneity", which involves variations in the ratio of the value of time $(\alpha)$ to the value of schedule delay $(\beta)$, with a fixed value of schedule delay: $\mu_{i} \equiv \alpha_{i} / \beta$. In the NCP case, the value of time is uniformly distributed between $€ 5.50$ and $€ 15.50$. Section 2 already noted that road externalities decrease with ratio heterogeneity, which lowers the gain from road tolling. The mean price of rail travel is unaffected by ratio heterogeneity, as the travel time of the train is fixed. The price of train travel for a user is now constant across services; with proportional heterogeneity, this price differed over services due to the differences in $\beta_{i}$.

\subsection{Base case no-congestion-pricing (NCP) and first-best equilibria with ratio heterogeneity}

Figure 8 gives the NCP prices including free-flow travel time and monetary costs. The price of rail travel increases linearly with the value of time when accounting for the fixed train travel time. The price of car travel increases concavely, and is highest for drivers with the highest ratio, as was also implied by equation (3). In this calibration, prices for train travel are higher than for 
car travel for all users. Nevertheless, the two modes are imperfect substitutes, and all values of time are represented in the train.

Figure 8: Prices including monetary costs and free-flow travel time

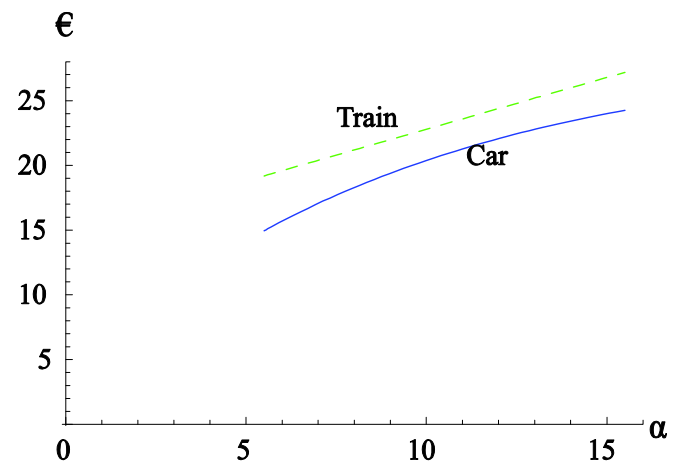

Table 7: Base case effects of the policies with ratio heterogeneity

\begin{tabular}{lcccccc}
\hline & NCP & TW & TP & CW & CP & FB \\
\hline Time-invariant train levy & - & $-€ 2.02$ & $€ 23.72$ & - & - & - \\
Time-invariant road toll & - & - & - & $-€ 0.68$ & $€ 22.17$ & - \\
Mean car-travel price $\left(\mathrm{E}\left[P^{C}\right]\right)$ & $€ 20.43$ & $€ 20.47$ & $€ 21.16$ & $€ 20.99$ & $€ 39.40$ & $€ 21.64$ \\
Mean train-travel price $\left(\mathrm{E}\left[P^{t}\right]\right)$ & $€ 23.19$ & $€ 24.30$ & $€ 46.87$ & $€ 23.19$ & $€ 23.69$ & $€ 26.13$ \\
Total toll revenue & - & - & & $€ 37,843$ & $€ 120,877$ & $€ 43,603$ \\
Total crowding levy revenue & - & $€ 6,588$ & $€ 64,949$ & - & - & $€ 15,717$ \\
Consumer Surplus & $€ 398,705$ & $€ 392,906$ & $€ 303,318$ & $€ 394,216$ & $€ 265,242$ & $€ 374,120$ \\
Welfare & $€ 398,705$ & $€ 399,494$ & $€ 368,267$ & $€ 432,059$ & $€ 386,119$ & $€ 433,441$ \\
Number of car driver $\left(\mathrm{N}^{\mathrm{c}}\right)$ & 9000 & 9035.5 & 9757.5 & 8887.7 & 4860.4 & 8859.2 \\
Number of train users $\left(\mathrm{N}^{\mathrm{t}}\right)$ & 5000 & 4881.6 & 2475.9 & 5018.3 & 5677.6 & 4726.0 \\
Relative efficiency & 0 & 0.023 & -0.876 & 0.960 & -0.362 & 1 \\
Percentage welfare gain & - & $0.20 \%$ & $-7.63 \%$ & $8.37 \%$ & $-3.16 \%$ & $8.71 \%$ \\
Percentage of NCP users & who & & & & & \\
would be better off & - & $0 \%$ & $0 \%$ & $30.3 \%$ & $0 \%$ & $13.8 \%$ \\
\hline
\end{tabular}

Again, road pricing gives a higher welfare gain than rail pricing. As Table 7 shows, CW pricing attains $96 \%$ of the first-best FB gain. The TW policy attains only $2 \%$. The train has about $35 \%$ of the users, so this large difference in welfare gain reflects more than just differences in the percentage of users who face congestion pricing.

Congestion pricing is less beneficial to the average user with ratio heterogeneity than with proportional heterogeneity or homogeneity. This is consistent with the two group example in Figure 1. With proportional heterogeneity, consumer surplus increases due to TW, CW, and FB policies. With ratio heterogeneity, only the second-best road pricing scheme $\mathrm{CW}$ increases consumer surplus before redistribution of revenues. The percentage of NCP (No-CongestionPricing) users who would face a lower price with pricing is also lower with ratio heterogeneity than with proportional heterogeneity. Table 7 shows that, with ratio heterogeneity, no user gains from TW pricing; with proportional heterogeneity in Table 2, all car drivers and $47 \%$ of rail users 
gain. Likewise, with ratio heterogeneity, $30 \%$ of NCP users gain from $\mathrm{CW}$ pricing; with proportional heterogeneity, all users gain. Finally, for all schemes, the welfare gain is lower with ratio heterogeneity than with proportional heterogeneity.

Figures 9 and 10 plot the price changes, compared to the NCP case, for train and car users. For train travel, the curves are flat lines, because only the cost of the fixed travel time depends on $\alpha_{i}$. This contrasts with proportional heterogeneity, where these curves are piecewise linear.

All rail users are affected to the same extent by pricing. Hence, pricing does not have distributional effects between rail users. Conversely, on the road there is a clear distributional pattern: road pricing is less harmful for a driver with a higher the value of time $(\alpha)$, because it lowers the car travel time. The rail-only pricing TW and TP raise travel times on the road, and are therefore more harmful for drivers with a higher $\alpha$. That a policy that increases travel time is less harmful with a lower value of time is logical, and was also found by Liu and Nie (2011), who study pricing in a large network and with two modes. It is worth noting that the signs of the slopes of the curves for drivers in Figures 7 and 10 are the same. In this regard, the distributional effects for drivers are thus similar for the two types of heterogeneity. But, as explained above, the signs of the effects (gains or losses) may differ.

Figure 9: Change in train-travel prices due to the pricing regimes
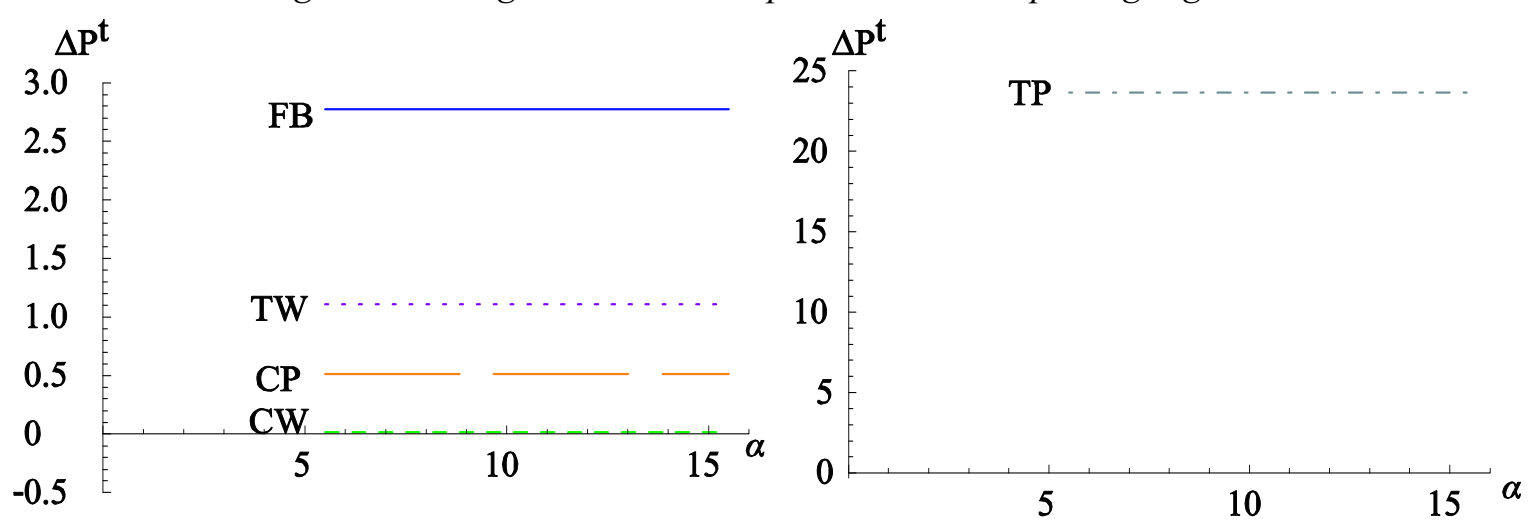

Figure 10: Change in car-travel prices due to the pricing regimes
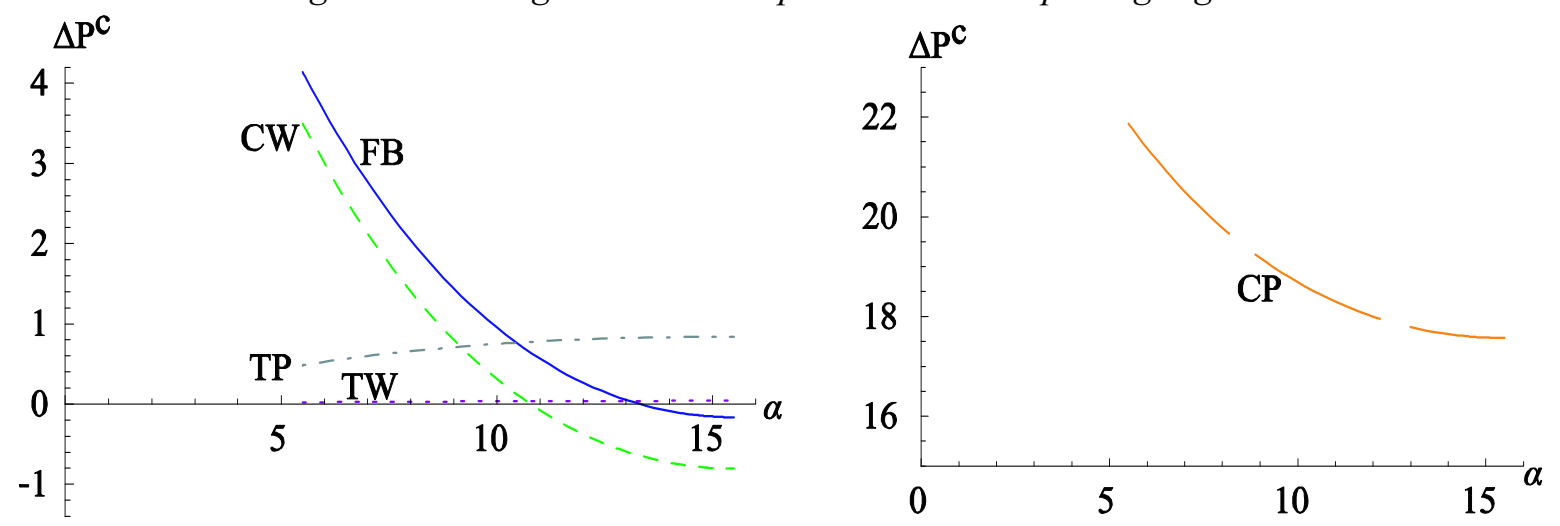


\subsection{Sensitivity analysis on the amount of ratio heterogeneity}

Table 8 analyses how the degree of heterogeneity in the ratio of values of time and schedule delay affects the NCP equilibrium. The base-case spread of the uniform distribution of $\alpha$ is 10; the other spreads are $10.8,9.2,6$, and $0 .{ }^{10}$ The mean value of time is always $€ 10.05$. Consumer surplus increases slightly with the spread, just as it did with proportional heterogeneity. But again this is due to the calibration, and does not represent a meaningful effect of heterogeneity. The average price of car travel decreases with the spread of $\alpha$, because the congestion externalities decrease (the price was insensitive with respect to the degree of proportional heterogeneity (see Table 3)). The mean price of train travel is unaffected, as the train travel time is fixed.

\section{Table 8: Ratio heterogeneity and the no-congestion-pricing (NCP) case}

\begin{tabular}{lccc}
\hline Spread of the value of time & $\mathrm{CS}$ & $\mathrm{E}\left[P^{C}\right]$ & $\mathrm{E}\left[P^{t}\right]$ \\
\hline 0 & $€ 418,250$ & $€ 21.75$ & $€ 23.19$ \\
6 & $€ 405,734$ & $€ 20.78$ & $€ 23.19$ \\
9.2 & $€ 400,052$ & $€ 20.52$ & $€ 23.19$ \\
10 (base case) & $€ 398,705$ & $€ 20.43$ & $€ 23.19$ \\
10.8 & $€ 396,925$ & $€ 20.34$ & $€ 23.19$ \\
\hline
\end{tabular}

Table 9 depicts the effects of the spread of $\alpha$ on the performance of first-best pricing. In contrast to proportional heterogeneity, ratio heterogeneity causes FB pricing to raise the average price for car travel. This was already implied by equations (3) and (4). Still, the price increase for rail travel is larger. This is, again, because congestion pricing is less beneficial with crowding congestion than with bottleneck congestion. The percentage FB welfare gain decreases with the spread. This is, as Section 2 argued, because externalities on the road decrease, which means that there is less to gain from tolling.

Table 9: Ratio heterogeneity and first-best pricing

\begin{tabular}{lccccccccc}
\hline $\begin{array}{l}\text { Spread of the value } \\
\text { of time }\end{array}$ & $\mathrm{E}\left[P^{C}\right]$ & $\mathrm{E}\left[P^{t}\right]$ & $\begin{array}{c}\text { Toll } \\
\text { revenue }\end{array}$ & $\begin{array}{c}\text { Fare } \\
\text { revenue }\end{array}$ & $\mathrm{CS}$ & Welfare & $\% \Delta W$ & $N^{c}$ & $N^{t}$ \\
\hline 6 & $€ 21.71$ & $€ 26.09$ & $€ 44,461$ & $€ 15,656$ & $€ 384,481$ & $€ 444,598$ & $9.6 \%$ & 8946.0 & 4712.9 \\
9.2 & $€ 21.65$ & $€ 26.13$ & $€ 43,770$ & $€ 15,706$ & $€ 376,097$ & $€ 435,573$ & $8.9 \%$ & 8876.1 & 4723.5 \\
10 (base case) & $€ 21.64$ & $€ 26.13$ & $€ 43,603$ & $€ 15,717$ & $€ 374,120$ & $€ 433,441$ & $8.7 \%$ & 8859.2 & 4726.0 \\
10.8 & $€ 21.60$ & $€ 26.13$ & $€ 43,448$ & $€ 15,726$ & $€ 371,768$ & $€ 430,942$ & $8.6 \%$ & 8843.4 & 4727.9 \\
\hline
\end{tabular}

Table 10 gives the welfare gains for different spreads of $\alpha$, and Table 11 the relative efficiencies. We again see that the gain from FB pricing decreases with the spread. The relative efficiencies of schemes that only price the road decrease with the degree of ratio heterogeneity. This corresponds with Van den Berg and Verhoef (2011b), where the relative efficiency of

\footnotetext{
${ }^{10}$ For a deterministic bottleneck equilibrium $\alpha_{i}>\beta$ must hold for all $i$. Hence, the maximum spread is 10.99 . However, for a spread above 10.8, the numerical model is unstable. Therefore, 10.8 used as the maximum spread.
} 
"single-link pricing" reduces with the degree of this heterogeneity. The welfare gain of TP is hardly affected by ratio heterogeneity. Still, its relative efficiency is more negative with a higher degree of ratio heterogeneity, because the first-best gain decreases, decreasing the denominator of the relative efficiency. The welfare gain and relative efficiency of TW marginally decrease with the spread of $\alpha$. With a larger spread, road externalities are smaller, and thus there is less to gain from attracting car drivers away from the road.

Table 10: Effect of ratio heterogeneity on percentage welfare gains

\begin{tabular}{lccccc}
\hline Spread of $\alpha$ & TW & TP & CW & CP & FB \\
\hline 0 & $0.62 \%$ & $-7.41 \%$ & $11.01 \%$ & $-1.55 \%$ & $11.42 \%$ \\
6 & $0.33 \%$ & $-7.59 \%$ & $9.24 \%$ & $-2.58 \%$ & $9.58 \%$ \\
9.2 & $0.23 \%$ & $-7.62 \%$ & $8.53 \%$ & $-3.05 \%$ & $8.88 \%$ \\
10 & $0.20 \%$ & $-7.63 \%$ & $8.37 \%$ & $-3.16 \%$ & $8.71 \%$ \\
10.8 & $0.19 \%$ & $-7.65 \%$ & $8.56 \%$ & $-3.26 \%$ & $8.57 \%$ \\
\hline
\end{tabular}

Table 11: Effect of ratio heterogeneity on relative efficiencies

\begin{tabular}{lcccc}
\hline Spread of $\alpha$ & TW & TP & CW & CP \\
\hline 0 & 0.054 & -0.649 & 0.966 & -0.136 \\
6 & 0.034 & -0.792 & 0.965 & -0.269 \\
9.2 & 0.026 & -0.859 & 0.961 & -0.343 \\
10 (base case) & 0.023 & -0.876 & 0.960 & -0.362 \\
10.8 & 0.022 & -0.893 & 0.958 & -0.381 \\
\hline
\end{tabular}

\subsection{Conclusions on ratio heterogeneity}

The welfare gains of all pricing schemes decrease when the degree of ratio heterogeneity (in $\alpha_{i} / \beta$ ) increases. Moreover, the relative efficiency of pricing only the road or train also decreases. With two roads, this type of heterogeneity had the same effect on the performance of first-best and second-best pricing. This contrasts with Section 4, where the effect of proportional heterogeneity differs between a two-roads and two-modes network.

\section{Some further sensitivity analyses}

\subsection{Operational cost}

Tabuchi (1993) analysed road and rail pricing when the rail operator's costs have a variable and fixed component; we assumed that it only has variable costs. To test the effects of this limitation, we redefined our models such that rail only has fixed cost. The fixed costs were set such that the average-operating cost in the NCP equilibrium equals the one in the foregoing simulations.

The effects of congestion pricing, and how heterogeneity affects these, remain roughly the same. The most notable difference is that, with fixed cost and second-best road-pricing (CW), it is beneficial to push users to the train since the fare is based on average operation cost instead of 
marginal operation cost. This result was also found by Tabuchi (1993). In the previous sections, the opposite effect (see, e.g., Braid, 1996) was found, where the priced road has a negative term in its toll to attract users from the crowded train.

Alternatively, there could be a variable cost to providing train services (instead of the cost per user). The number of services would then be a discrete capacity variable, which would be set following cost-benefit analysis. It would then also be necessary consider the optimisation of road capacity. See also Arnott et al. $(1988,1994)$ on the effects of capacity expansion in the bottleneck model under heterogeneity, Arnott and Yan (2000) on (second-best) capacity setting in a road and rail network, and Yang, Kong and Meng (2001) on frequency and fare setting of two bus operators when there is competition from the untolled car and heterogeneity in the value of time.

\subsection{Price elasticities}

The effects of changing own-price elasticities are in line with the results in the earlier literature. In particular, private pricing is increasingly harmful with less elastic demand, because the company's market power increases. Changing the cross-elasticity is more interesting. It could be that the limited relative efficiency of second-best TW train pricing that we found stemmed from a low cross-elasticity, as this makes it difficult to attract drivers away from the unpriced road.

In the ratio heterogeneity model, the highest cross-elasticity of rail demand w.r.t. the price of car travel consistent with utility maximisation is 0.379 (see also footnote 6). In the base case, this elasticity was 0.1 . This almost quadrupling raises the TW's relative efficiency by $314 \%$ to 0.095 . Nevertheless, it remains low and far below the relative efficiency of road-only pricing. With proportional heterogeneity, the maximum cross-elasticity is 0.37 . Here the relative efficiency for TW increases by $201 \%$ to 0.10 . In conclusion, the limited cross-elasticity is not the most important reason for the low gain from rail pricing.

\subsection{Crowding costs}

Another reason for the low gain of rail pricing could be a relatively low value of crowding. Although it seems likely that crowded trains indeed cause a discomfort, we have little empirical information on the value of crowding for our model. To gain insight, we double the crowding coefficient $g$. This less than doubles total crowding costs, as users respond by arriving more spread out over the day. In the ratio heterogeneity model, the mean NCP price increases by $€ 3.27$ to $€ 26.46$. Yet, the relative efficiency of TW pricing only increases by $11 \%$ to 0.025 . The relative efficiency of private TP increases from -0.876 to -0.38 . With proportional heterogeneity, the doubling of $g$ raises TW's relative efficiency by $17 \%$ to 0.04 .

All this suggests that the value of crowding congestion does have an effect. But the primary reason for the low gain from rail pricing relative to road pricing seems to be the difference 
between bottleneck and crowding congestion. With bottleneck congestion, pricing removes the pure waste that is queuing. The train has no purely wasteful congestion.

\section{Conclusion}

This paper analysed congestion pricing in a road and rail network with heterogeneous users, where the train and car are imperfect substitutes. We separately studied "ratio heterogeneity", in the ratio of value of time to value of schedule delay, and "proportional heterogeneity", which varies both values in fixed proportions.

With proportional heterogeneity, road pricing makes the arrival order more efficient, thereby lowering scheduling costs. Accordingly, the welfare gain of road pricing increases with this type of heterogeneity. The relative efficiency of private road-only pricing rises with proportional heterogeneity, while for welfare maximisation the relative efficiency decreases. This contrast with earlier findings for two roads, where the relative efficiency of "single-link pricing" was found to increase with proportional heterogeneity (Van den Berg and Verhoef, 2011a). The difference was found to be because two roads are perfect substitutes, while car and train are not in our setting.

On the rail link, users always arrive in order of increasing value of schedule delay. Thus, pricing cannot improve the arrival order. The welfare gain of rail-congestion pricing is hardly affected by proportional heterogeneity. Still, the relative efficiency of private rail-only-pricing slightly decreases with this type of heterogeneity.

A general conclusion is that the gain of congestion pricing can be lower or higher with heterogeneity depending on the types and extents of the heterogeneity. Nevertheless, pricing always leads to a welfare improvement. Perhaps more important for policy are the distributional effects, which differ strongly between road and rail. In the train, pricing has no distributional effects or is more harmful for users with higher values of time and schedule delay. On the road, generally, users with a higher value of time or schedule delay are more likely to benefit from road pricing. Conversely, private rail pricing is more damaging for road users with higher values of time or schedule delay, because it increases congestion on the road, and this is more costly with higher values. The distributional effects thus need not follow the expected pattern where a higher value of time or schedule delay makes a user better off with congestion pricing.

An interesting extension of our model would be to consider heterogeneity in the value of crowding. Then, users with high crowding values would arrive early in relatively empty trains, and low-value users would arrive close to the preferred arrival time. Hence, crowding externalities will be lower with heterogeneity, thus lowering the gains from rail pricing. Accordingly, the effect of value-of-crowding heterogeneity in the rail model might be similar to that of ratio heterogeneity in the bottleneck model. Then it would also be interesting to introduce 
first and second class coaches, as users could self-select by value of crowding, thereby lowering total costs. If we used a crowding multiplication of the value of time following the empirical literature, instead of separate crowding and travel time costs, the effect of heterogeneity on rail might also be similar to that on road pricing. Another interesting extension would be to study a

larger network, to see how the things we study work out in a more realistic setting.

\section{Acknowledgements}

We thank Robin Lindsey, Stef Proost, Jan Rouwendal, Erik Kroes, Mrs. Ellman, and Muhammed Sabir for their comments. This research was financially supported by Transumo and ERC (AdG Grant \#246969 OPTION). The usual disclaimer applies.

\section{References}

Arnott, R., de Palma, A., Lindsey, R., 1988. Schedule delay and departure time decisions with heterogeneous commuters. Transportation Research Record 1197, 56-67.

Arnott, R., de Palma, A., Lindsey, R., 1994. The welfare effects of congestion tolls with heterogeneous commuters. Journal of Transport Economics and Policy 28(2), 139-161.

Arnott, R., Yan, A., 2000. The two-mode problem: Second-best pricing and capacity. Review of Urban and Regional Development Studies 12(3), 170-199.

Braid, R.M., 1996. Peak-load pricing of a transportation route with an unpriced substitute. Journal of Urban Economics 40(2), 179-197.

Chu, X., 1995. Endogenous trip scheduling: the Henderson approach reformulated and compared with the Vickrey approach. Journal of Urban Economics 37(3), 324-343.

de Palma, A., Lindsey, R, 2002. Congestion pricing in the morning and evening peaks: a comparison using the Bottleneck Model. In: Proceedings of the 39th Annual Conference of the Canadian Transportation Research Forum: 2002 Transportation Visioning - 2002 and Beyond, Vancouver, Canada, May 2002, 179-193, Canada, 9-12 May 2004, 179-193.

Huang, H.-J., 2000. Fares and tolls in a competitive system with transit and highway: the case with two groups of commuters. Transportation Research Part E 36(4), 267-284.

Kraus, M., 1991. Discomfort externalities and marginal cost transit fares. Journal of Urban Economics 29(2), 249259.

Kraus, M., 2003. A new look at the two-mode problem. Journal of Urban Economics 54(3), 511-530.

Kraus, M., Yoshida, Y., 2002. The commuter's time-of-use decision and optimal pricing and service in urban mass transit. Journal of Urban Economics 51(1), 170-195.

Layard, R., 1977. The distributional effects of congestion taxes. Economica 44(175), $297-304$.

Li, Z., Hensher, D.A. 2011. Crowding and public transport: a review of willingness to pay evidence and its relevance in project appraisal. Transport Policy 18(6), 880-887.

Lindsey, R., 2004. Existence, uniqueness, and trip cost function properties of user equilibrium in the bottleneck model with multiple user classes. Transportation Science 38(3), 293-314.

Liu, Y., Nie, Y., 2011. Welfare effects of congestion pricing and transit services in multi-class multi-modal networks (version of 1Augustus 2011). In: Transportation Research Board, the $91^{\text {th }}$ Annual Meeting of the Transportation Research Board, Washington D.C., USA.

Rouwendal, J., Verhoef, E.T., 2004. Second best pricing for imperfect substitutes in urban networks. In G. Santos (Ed.), Road pricing: Theory and evidence. Research in transportation economics (Vol. 9). pp. 27-60. Oxford: Elsevier.

Small, K.A., Verhoef, E.T., 2007. The Economics of Urban Transportation. London, Routledge.

Small, K.A., Yan, J., 2001. The value of "value pricing" of roads: second-best pricing and product differentiation. Journal of Urban Economics 49(2), 310-336.

Tabuchi, T., 1993. Bottleneck congestion and modal split. Journal of Urban Economics 34(3), 414-431. 
van den Berg, V.A.C., Verhoef, E.T., 2011a. Winning or losing from dynamic bottleneck congestion pricing? The distributional effects of road pricing with heterogeneity in values of time and schedule delay. Journal of Public Economics, 95(7-8), 983-992.

van den Berg, V.A.C., Verhoef, E.T., 2011b. Congestion tolling in the bottleneck model with heterogeneous values of time. Transportation Research Part B 45(1), 60-70.

Verhoef, E.T., Small, K.A., 2004. Product differentiation on roads: constrained congestion pricing with heterogeneous users. Journal of Transport Economics Policy 38(1), 127-156.

Vickrey, W.S., 1969. Congestion theory and transport investment. American Economic Review (Papers and Proceedings) 59(2), 251-260.

Vickrey, W.S., 1973. Pricing, metering, and efficiently using urban transportation facilities. Highway Research Record 476, 36-48.

Wardman, M., Whelan, G.A., 2011. 20 Years of rail crowding valuation studies: evidence and lessons from British experience. Transport Reviews 31(3), 379-398.

Wu, W.-X., Huang, H.-J., 2010. Equilibrium and modal split in a competitive highway/transit system under different road-use pricing regimes. Workingpaper of Beijing University of Aeronautics and Astronautics, version of 2 december 2010.

Yang, H., Kong, H.Y, Meng, Q. 2001. Value-of-time distributions and competitive bus services. Transportation Research Part E 37 (6), 411-424. 